\title{
Long-Chain Alkylimidazolium Ionic Liquid Functionalization of Cellulose Nanofibers and Their Embedding in HDPE Matrix
}

\author{
Catalin Croitoru ${ }^{1}$ and Silvia Patachia ${ }^{2}$ \\ ${ }^{1}$ Materials Engineering and Welding Department, Transilvania University of Brasov, 29 Eroilor Street, 500036 Brasov, Romania \\ ${ }^{2}$ Product Design Mechatronics and Environment, Transilvania University of Brasov, 29 Eroilor Street, 500036 Brasov, Romania \\ Correspondence should be addressed to Catalin Croitoru; c.croitoru@unitbv.ro and Silvia Patachia; st.patachia@unitbv.ro
}

Received 26 February 2016; Revised 23 May 2016; Accepted 31 May 2016

Academic Editor: Ang Lu

Copyright (C) 2016 C. Croitoru and S. Patachia. This is an open access article distributed under the Creative Commons Attribution License, which permits unrestricted use, distribution, and reproduction in any medium, provided the original work is properly cited.

\begin{abstract}
This paper presents a possible alternative to traditional cellulose nanofibers functionalization, by treatment of the material at low temperatures $\left(25-35^{\circ} \mathrm{C}\right)$ with electron-beam irradiated 1-hexyl-3-methylimidazolium chloride ionic liquid. The treatment promotes decreasing the crystallinity of the cellulose with up to $45 \%$ and possible imidazolium moieties grafting to cellulose, as demonstrated from FTIR, XRD, and elemental analysis. The grafting determines water vapors uptake values with 50-70\% lower and water vapors uptake rate with $50 \%$ lower than those of reference cellulose nanofibers. The grafting determined also improved adhesion of the cellulose nanofibers to HDPE, thus contributing to the obtaining of polymer matrix composites with improved properties.
\end{abstract}

\section{Introduction}

Natural wood fibers and nonwood natural biofibers, as well as highly crystalline cellulose-derived products such as cellulose nanofibers, could be used as relatively inexpensive fillers in a large variety of thermoplastic (PE, PP) $[1,2]$ as well as thermoset resin (epoxi, phenol-based) [3] polymeric matrix composites. These fillers present a large variety of applications in the construction and automotive industry, due to their bioavailability, low machine wear in processing, low density compared to traditional inorganic fillers, and low price, coupled with high impact resistance, owing to their highly crystalline oriented cellulose I anomer structure (crystallinity index usually above 75\%) [4-6].

Cellulose nanofibers (CelNFs) could be produced from a wide variety of sources, such as paper, wood pulp, and natural cellulose fibers, through time and temperature controlled enzymatic or acid hydrolysis, selectively hydrolyzing only the amorphous part of the macromolecular cellulose chains [7].

However, due to the hydrophilic nature of cellulose, the majority of the obtained composites bear a cellulosecompatible polar polymeric matrix. There have been considerably few studies involving the obtaining of composites with polyolefin matrix. In order to use CelNFs as fillers in polyolefin matrix composites, their surface must be modified either by physical (e.g., plasma grafting of fluorine or silicon atoms on the nanocellulose fibril surface) [8] or by chemical functionalization (esterification or coupling agent treatment); otherwise, poor mechanical properties and delamination could occur $[9,10]$.

Surface treatment of CelNF via physical and/or chemical modification methods is important to tailor CelNF surfaces for application in specific polymer matrices, in terms of both compatibility and controlling their aggregation, and is still an ongoing research. Several studies have been performed regarding the surface modification of cellulosic nanofibers, through grafting to the cellulose $-\mathrm{OH}$ groups of lowpolarity moieties via organic (acrylates, anhydrides, chlorotriazines, and their derivatives, isocyanates, monomers, etc.) or hybrid organic-inorganic (silanes and titanates) functionalization agents [10]. Many of these functionalization agents require the use of volatile organic solvents (dichloromethane, toluene) and initiators which possess an environmental risk due to their volatility and toxicity. Only a few researches are available regarding the use of more polyolefin-compatible natural cellulosic materials, such as chitin-cellulose fibers [11].

Ionic liquids (ILs) are considered as mild solvents, with low volatility and good chemical and thermal stability [12]. 
In particular, short chain alkylimidazolium halides and acetates (with 1-alkyl 3-methylimidazolium cations, especially ethyl, butyl, or allyl) have been employed as energetic and environmental friendly lignocellulosic mass dissolution and/or fractionation [13] or even as solvents for cellulosefunctionalizing agents (anhydrides, acyl chlorides) [14], while longer chain ionic liquids (1-hexyl-3-methylimidazolium, 1dodecyl-3-methylimidazolium, and higher) in conjunction with other types of anions (such as tetrafluoroborate, hexafluorophosphate, and bis(triflluoromethylsulfonyl)imide), though possessing a significantly lower cellulose-dissolution ability, have potential use as cellulose plasticizers [15], antistatic agents [16, 17], UV-stabilizers [15], or antifungal agents [18] for cellulose and wood materials, as demonstrated also from our previous studies on cellulose and wood [19].

This paper presents an alternative method of cellulose nanofibers functionalization through low temperatures $\left(25-35^{\circ} \mathrm{C}\right)$ surface modifying of cellulose nanofibers with long-chain imidazolium moieties, achieved by simple treatment of the cellulosic material with beta-irradiated 1hexyl-3-methylimidazolium tetrafluoroborate ionic liquid. The nanofibers have been obtained through the acid hydrolysis method starting from cotton linters, due to their high cellulose content and high purity and their availability, being a byproduct of the textile industry.

Alteration of cellulose nanofibers features after treatment with irradiated long-chain imidazolium based ionic liquids is demonstrated by structural (FTIR) and elemental analysis and indirectly through the increasing in the compatibility of the obtained functionalized fibers with a typical nonpolar HDPE matrix. This study is aimed at extending our previous work involving the grafting of imidazolium moieties on cellulosic materials, through electron-beam (EB) irradiation of ionic liquid impregnated wood [19].

\section{Materials and Methods}

1-Hexyl-3-methylimidazolium tetrafluoroborate ionic liquid $\left(\mathrm{HMIMBF}_{4}\right)$ of $99.5 \%$ purity has been purchased from IoLiTec Ionic Liquids Technologies GmbH, Germany, and used as provided in the EB irradiation tests.

HDPE with an average molecular weight of 40000 , density of $0.95 \mathrm{~g} / \mathrm{cm}^{3}$, a mass melt flow index (MFI) value of $4.23 \mathrm{~g} / \mathrm{min}$ at $190^{\circ} \mathrm{C}$, and $2.16 \mathrm{~kg}$ piston weight has been used for the CelNFs-HDPE composites obtaining.

2.1. CelNFs Obtaining. The cellulose nanofibers have been prepared through a combination of both acid hydrolysis and ultrasonication methods starting from cotton linters. The cotton linters have been dewaxed with a $2: 1(\mathrm{v} / \mathrm{v})$ mixture of benzene and ethanol according to the procedure described by Abu-Rous et al. [20], followed by washing and soaking the linters for $24 \mathrm{~h}$ in a $5 \% \mathrm{KOH}$ solution, in order to remove all potential impurities.

The acid hydrolysis of cotton linters has been performed using a $33 \%$ wt. sulfuric acid solution at $90^{\circ} \mathrm{C}$ for 60 minutes, so that the ratio of cellulose to the acid solution is $1: 10 \mathrm{wt}$. Then, distilled water has been added at room temperature in order to stop the hydrolysis reaction. The resulting cellulosic material has been decanted and washed with distilled water several times until reaching a neutral $\mathrm{pH}$ value. The volume ratio between the resulting cellulosic material and water has been brought to $1: 10$ and the resulting dispersion has been sonicated for $24 \mathrm{~h}$ at $25^{\circ} \mathrm{C}$.

\subsection{Ionic Liquids EB Irradiation and CNFs Treatment.} Electron-beam exposure experiments of the $\mathrm{HMIMBF}_{4}$ ionic liquid have been performed at the Electron Accelerator Laboratory from the National Institute for Lasers, Plasma and Radiation Physics, Bucharest, with the ALIN-10 electron linear accelerator (6.23 MeV energy, $100 \mathrm{~Hz}$ beam impulse). The EB dose rate has been $2.4 \mathrm{kGy} / \mathrm{min}$, so as to finally accumulate $50 \mathrm{kGy}$ at the end of the exposure period.

2.3. Cellulose Nanofibers Ionic Liquid Treatment. The CNFs, separated from the distilled water, have been placed in the irradiated ionic liquid, in stoppered glass vials, so that the ratio of cellulose to the irradiated ionic liquid is $1: 10 \% \mathrm{wt}$. The treatment involved magnetic stirring of the CelNF-IL system for $24 \mathrm{~h}$ at two temperatures, namely, $25^{\circ} \mathrm{C}$ and $35^{\circ} \mathrm{C}$, respectively.

After ionic liquid treatment, the cellulose nanofibers have been washed several times with ethanol and distilled water. The elimination of ionic liquid has been monitored conductometrically.

The resulted CelNF suspension, priorly concentrated through decantation, has been submitted to freeze-drying (Christ Alpha 1-2 LD Plus lyophilizer) at $-80^{\circ} \mathrm{C}$ and $1 \mathrm{mbar}$ for $24 \mathrm{~h}$, in order to completely remove the water from the structure. This operation is necessary for performing the FTIR and elemental analysis, as well as for obtaining the polyolefin composites.

2.4. CelNFs-HDPE Composites Obtaining. Two types of CelNFs-HDPE composites have been obtained through thermoforming, by using a $10 \%$ wt. weight ratio of CelNFs reported to HDPE: (1) reference samples, with neat cellulose nanofibers, and (2) samples with irradiated IL-treated CelNFs at both $25^{\circ} \mathrm{C}$ and $35^{\circ} \mathrm{C}$, respectively.

The ground HDPE ( $<0.5 \mathrm{~mm}$ mesh) and CelNFs have been pressed at $50 \mathrm{~atm}$ and then maintained at $230^{\circ} \mathrm{C}$ for $1 \mathrm{~h}$, followed by cooling at room temperature. The obtained composites dimensions were $100 \times 10 \times 5 \mathrm{~mm}$ (length $\times$ width $\times$ thickness). The degradation of cellulose nanofibers at $230^{\circ} \mathrm{C}$ is minimal, as determined from FTIR spectroscopy results.

2.5. FTIR Analysis. The FTIR spectra of the $\mathrm{HMIMBF}_{4}$ ionic liquid, before and after EB irradiation in the $4000-600 \mathrm{~cm}^{-1}$ interval with a resolution of $2 \mathrm{~cm}^{-1}$, as well as of untreated and IL-treated CelNFs were obtained with a Bruker Vertex 70 spectrometer equipped with a Golden-Gate ATR device. The FTIR spectra in the $4000-600 \mathrm{~cm}^{-1}$ interval of the reference and EB-irradiated $\mathrm{HMIMBF}_{4}$ ionic liquid, placed between two potassium bromide windows, have been obtained with 
the same spectrometer in transmittance mode, after freezedrying the IL in the same conditions as those described in Section 2.3.

2.6. SEM and Elemental Analysis. A scanning electron microscope (SEM) QUANTA 200 was used to study the morphological appearance of the obtained CelNF and of the CelNFHDPE composites cross sections. The composite samples have been analyzed without any further treatments.

$\mathrm{C}$ and $\mathrm{N}$ weight percent in the neat and treated CelNFs have been determined by using an elemental EuroVector EA 3000 analyzer.

2.7. XRD Analysis. The crystalline structure of the cotton linters, cellulose nanofibers, and ionic liquid-treated nanofibers has been determined by using an Advanced D8 Discover Bruker diffractometer, $K_{\alpha 1}=1.5406 \AA, 40 \mathrm{~kW}, 20 \mathrm{~mA}$, scan speed $2^{\circ} / \mathrm{min}, 2 \theta$ range from 5 to $40^{\circ}$, under laboratory conditions (atmospheric pressure, $25^{\circ} \mathrm{C}$, and $45 \%$ relative humidity).

The diffractograms of all the CelNFs (reference and ILtreated) have been deconvoluted using Gaussian profiles, aiming at accurate matching of the cumulative fit curve to the experimental curve.

The crystallinity percent has been calculated from the XRD diffractograms presented in Figure 2 with (1), from the data obtained after deconvolution [21]:

$$
\mathrm{Cr}=\frac{A_{\text {cryst }}}{A_{\text {total }}} \cdot 100,
$$

where $A_{\text {cryst }}$ represents the area of the peaks corresponding to the crystalline fraction and $A_{\text {total }}$ represents the total area under the diffractogram.

The apparent cellulose I crystallite size $(L)$ was estimated with the use of the Scherrer equation as follows [21]:

$$
L=\frac{K \cdot \lambda}{\beta \cdot \cos \theta},
$$

where $K$ is a constant with a value of $0.94(\% / \mathrm{min})$ for cellulose, $\lambda$ is the X-ray diffractometer wavelength $(0.1542 \mathrm{~nm}), \beta$ is the width of the diffraction peak at half of the intensity $\left({ }^{\circ}\right)$, and $\theta$ is the Bragg angle corresponding to the (002) diffraction plane.

The apparent crystallite size relates to the dimensions of the perfect crystallite size $(100 \%$ crystalline, cellulose I, not including the poorly arranged surface chains). It could provide additional information about structural organizations in the macromolecular architecture of cellulose. A looser structure with a lower crystallinity and a higher cellulose II content would present lower value of the $L$ parameter.

A relative proportion of cellulose crystallite interior chains $(X)$ can be calculated as follows, taking into account that the surface chains occupy an approximately $0.57 \mathrm{~nm}$ layer [22]:

$$
X=\frac{(L-2 h)^{2}}{L^{2}},
$$

where $L$ is the apparent crystallite size for the reflection of plane (200) and $h=0.57 \mathrm{~nm}$ is the layer thickness of the surface chain, calculated by taking into consideration the crystalline monoclinic and triclinic structures of cellulose.

2.8. Water Sorption Isotherms. In order to determine the water vapors sorption behavior of CelNFs, sorption isotherms have been determined by placing predried pelletized reference and irradiated IL-treated CelNFs samples of determined mass $\left(m_{i} \sim g\right.$, diameter $15 \mathrm{~mm}$, and $1 \mathrm{~mm}$ thickness, pressed at $30 \mathrm{~atm}$ with a hydraulic press) into desiccators with saturated inorganic aqueous salts solutions at $25^{\circ} \mathrm{C}$. The inorganic salts have been chosen accordingly [23] in order to ensure a relative humidity interval between $4 \%$ and $98 \%$ inside the desiccator. At determined time intervals, the samples in the desiccators have been weighed and the value corresponding to the equilibrium water sorption has been registered $\left(m_{f}\right)$.

The relative water sorption amount at equilibrium for each $\mathrm{RH}$ value, $w$, has been calculated with

$$
w(\%)=\frac{\left(m_{f}-m_{i}\right)}{m_{i}} \cdot 100 .
$$

\section{Results and Discussion}

The resulting cellulose nanofibers obtained through acid hydrolysis of cotton linters have an average diameter of $32.5 \mathrm{~nm}$, in agreement with the data presented in the reference literature [7] as it can be observed from the fiber diameter distribution histogram in Figure 1.

After ionic liquid treatment, an increase in the fibers' relative diameter with up to $35 \%$ could be observed, due to both structural modifications that occur in the cellulose macromolecular assembly and crystallinity and possible imidazolium cation grafting on the fibers, as suggested from the SEM micrographs, presented in Figure 1, and also sustained by spectroscopic data (Table 1 and Figure 2). Also, an elemental $\mathrm{C}$ and $\mathrm{N}$ percentage increase in the irradiated$\mathrm{HMIMBF}_{4}$ treated CelNFs at $35^{\circ} \mathrm{C}$ may suggest possible functionalization of cellulose with the partially hydroxylated imidazolium moiety, possibly by ether bonds.

The FTIR spectra of the neat and functionalized cellulose samples are presented in Figure 2. All the cellulose samples shown in Figure 2(a) present in general two main absorbance regions. The first one, at low wavelengths in the 4000$1700 \mathrm{~cm}^{-1}$ range $\left(\mathrm{Cel}_{\mathrm{I}}\right)$, comprises a few absorption bands such as the broad one from $3450-3400 \mathrm{~cm}^{-1}$ ascribed to $\mathrm{OH}$ stretching; the overlapping ones from $2930-2910 \mathrm{~cm}^{-1}$, ascribed to different $\mathrm{C}-\mathrm{H}$ stretching modes from methyl and methylene groups; and those found at $1765-1715 \mathrm{~cm}^{-1}$, ascribed to $\mathrm{C}=\mathrm{O}$ resulting from the oxidation of the terminal $-\mathrm{C}-\mathrm{OH}$ groups [24-28]. The second region, in the 1700$600 \mathrm{~cm}^{-1}$ domain $\left(\mathrm{Cel}_{\mathrm{II}}\right)$, is more rich in absorption bands, including the fingerprint ones. The band at $1640 \mathrm{~cm}^{-1}$ could be assigned to weakly adsorbed water. The bands in the $1462-1425 \mathrm{~cm}^{-1}$ domain are ascribed to asymmetric C-H stretching and bending vibration modes in the pyran ring 


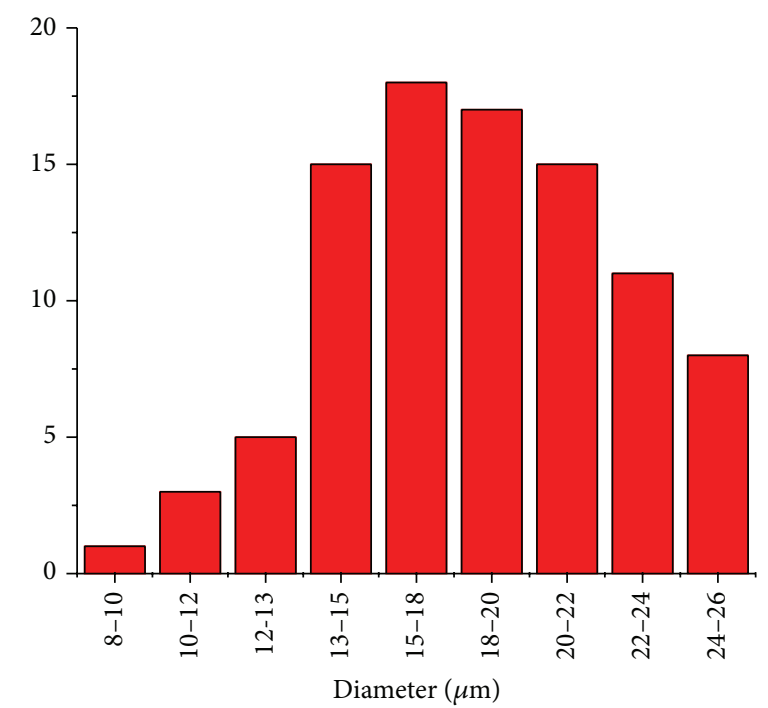

(a)
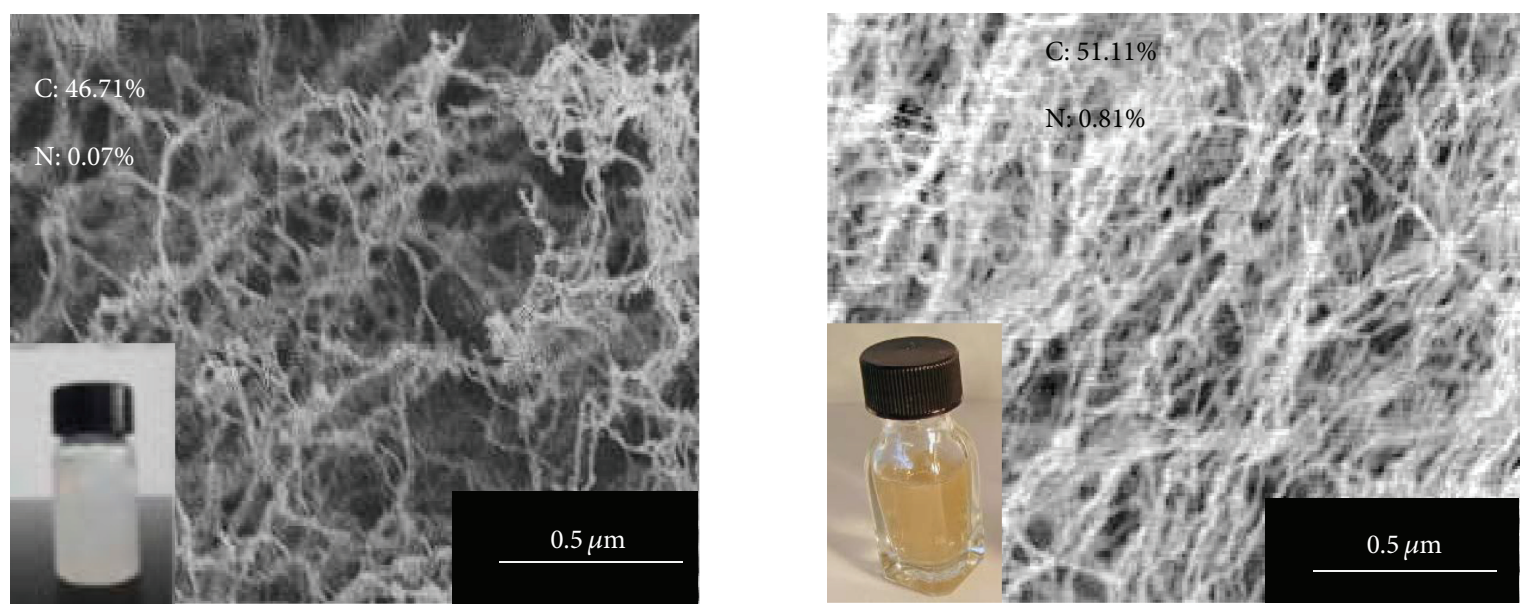

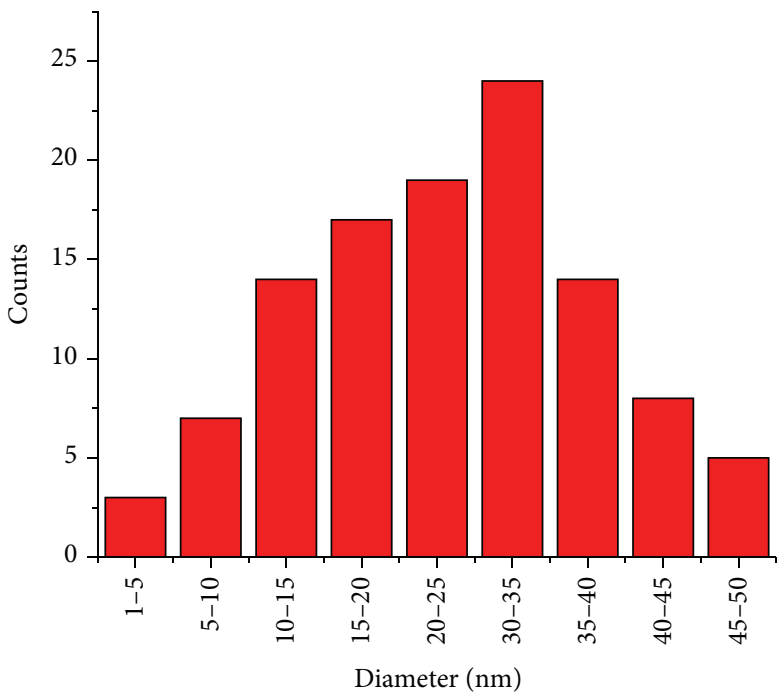

(b)

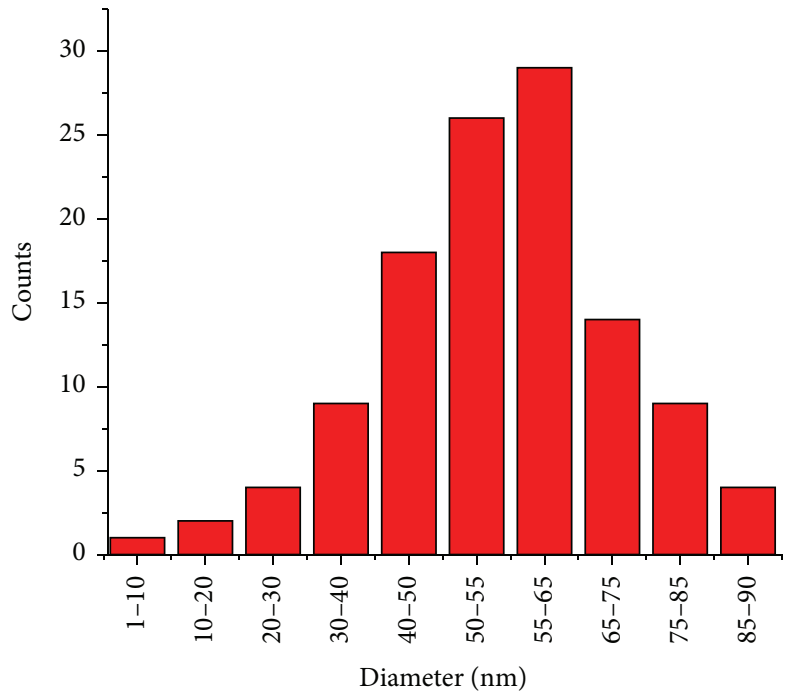

(c)

FIGURE 1: Fiber diameter distribution of initial cotton linters (obtained by optical microscopy) (a), of hydrolyzed cotton fibers (reference) (b), and of IL-treated CelNFs (SEM) (c) and elemental (C, N) content of reference and IL-treated CelNFs (b and c). 


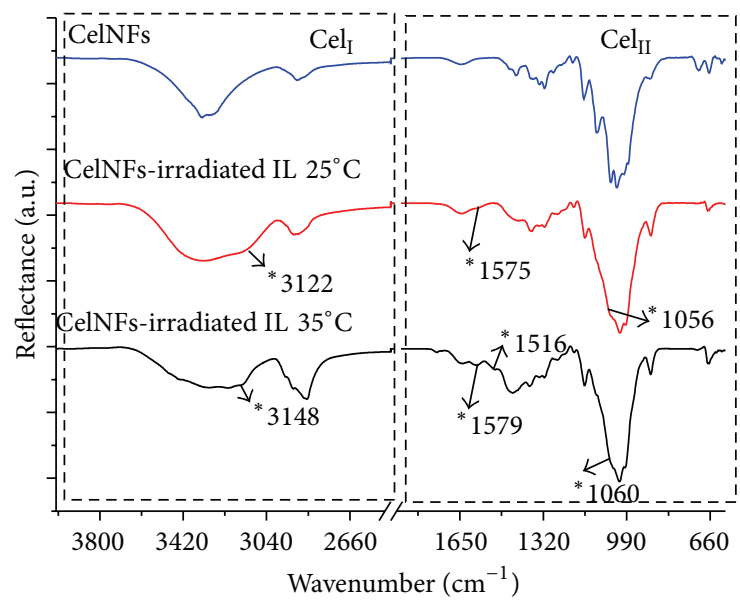

(a)

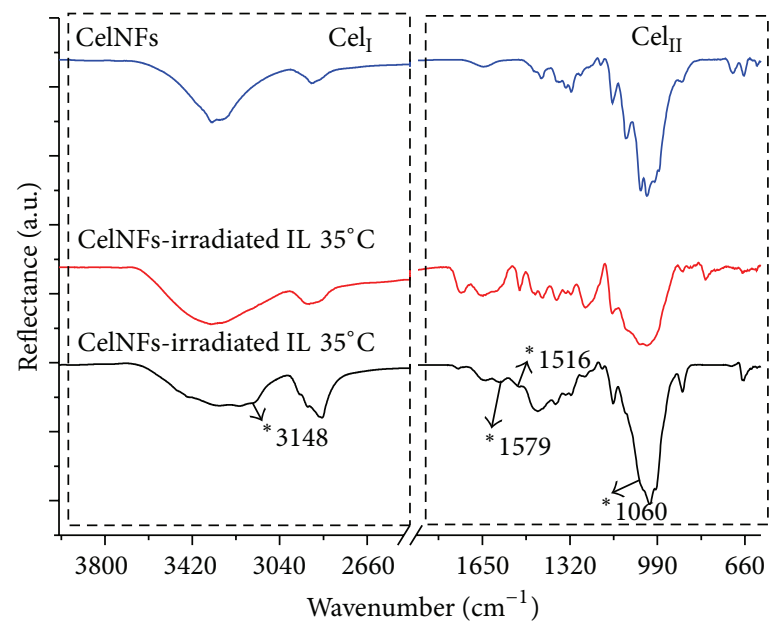

(c)

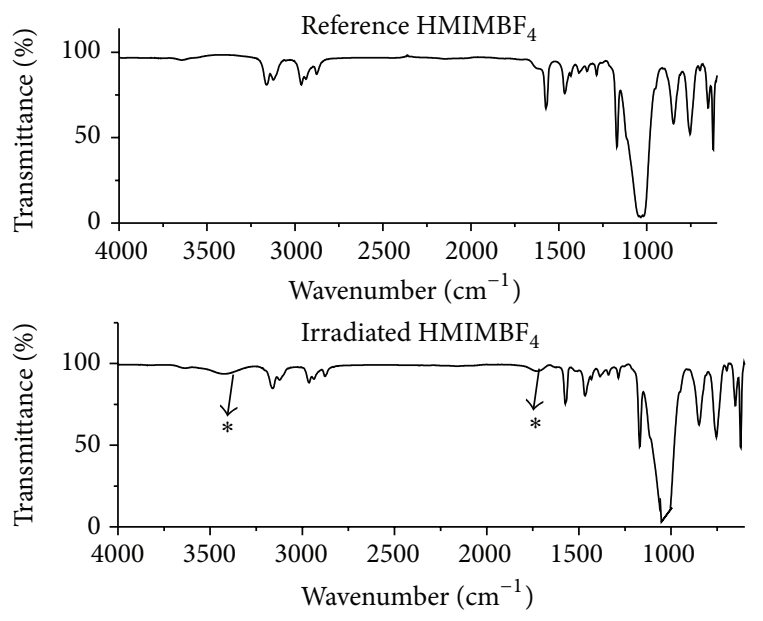

(b)

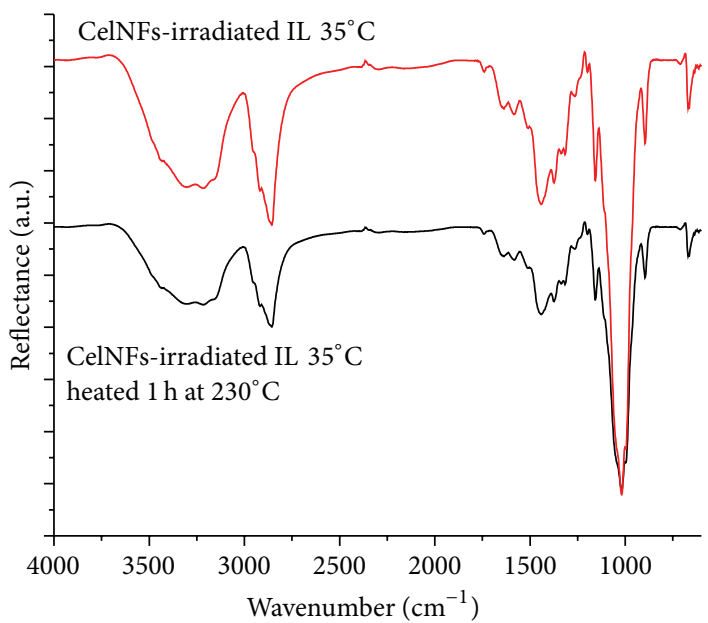

(d)

Figure 2: FTIR spectra of (a) irradiated IL-treated CelNFs at $25^{\circ} \mathrm{C}$ and $35^{\circ} \mathrm{C}$; (b) neat and irradiated $\mathrm{HMIMBF}_{4}$; (c) irradiated and neat ILtreated CelNFs at $35^{\circ} \mathrm{C}$; and (d) irradiated IL-treated CelNFs at $35^{\circ} \mathrm{C}$ as such and heated at $230^{\circ} \mathrm{C}$. ${ }^{*}$ Changes in the spectra pattern related to possible alkylimidazolium grafting to cellulose (c).

of the glucose unit, $\mathrm{CH}$ bending in cellulose I and cellulose II $\left(1375-1365 \mathrm{~cm}^{-1}\right), \mathrm{C}-\mathrm{H}$ deformation in cellulose I and cellulose II (1282-1277 $\left.\mathrm{cm}^{-1}\right)$, and $\mathrm{C}(1)-\mathrm{O}-\mathrm{C}(4)$ asymmetric stretching in cellulose I and cellulose II $\left(1162-1125 \mathrm{~cm}^{-1}\right)$ [26].

The EB radiation at doses of $50 \mathrm{kGy}$ is responsible for imidazolium ring scission, especially at $\mathrm{C}(2)-\mathrm{H}$ and $\mathrm{C}(5)-$ $\mathrm{H}$ in the imidazolium ring, as determined from our previous research and from the reference literature for other more energetic irradiation types (X-ray, $\gamma$ ) $[27,28]$. This scission could account for the formation of free radicals and imidazolium oligomers, but more important for this study is the hydroxylation of the imidazolium cation in the presence of trace amounts of absorbed water [16], which could explain the occurrence of a new band, centered at $3400 \mathrm{~cm}^{-1}$ (marked with asterisk in Figure 2(b)) in the FTIR spectrum of the EB-irradiated $\mathrm{HMIMBF}_{4}$. Also carbonyl groups are formed possibly through terminal chain oxidation and/or imidazolium ring scission at $\sim 1740 \mathrm{~cm}^{-1}$ (marked with asterisk in Figure 2(b)). The $\mathrm{BF}_{4}{ }^{-}$anion, having an absorption band centered at $1135 \mathrm{~cm}^{-1}$, is reported to be relatively stable to irradiation $[29,30]$.

The FTIR spectra of the irradiated IL-treated CelNFs (Figure 2(a)) present some particularities, namely, the overall shifting of all the main characteristic absorption bands to lower wavenumbers, associated with the flexibilization of the cellulose macromolecular architecture, due to the conversion of the cellulose I anomer, possessing higher crystallinity, to the dominating amorphous cellulose II anomer, reflected through the decrease in the crystallinity index (CrI) and lateral order index (LOI) of the IL-treated cellulose nanofibers (also sustained from the data obtained from the XRD diffractograms and from our previous results regarding ionic liquid treatment of cellulosic materials [15]). The shift is more pronounced with the increasing in the EB-irradiated IL treatment temperature.

CrI can be calculated as the area ratio of the bands at 1371 and $1156 \mathrm{~cm}^{-1}$ and the LOI, related to the proportion of cellulose I from the sample, as the ratio between the $1430 \mathrm{~cm}^{-1}$ 
TABLE 1: Cellulose structural parameters obtained from FTIR and XRD spectra.

\begin{tabular}{lccccc}
\hline \multirow{2}{*}{ Material } & \multicolumn{2}{c}{ FTIR analysis } & \multicolumn{3}{c}{ XRD analysis } \\
& CrI & LOI & Cr (\%) & $L(\mathrm{~nm})$ & $X$ \\
\hline CelNFs & 0.084 & 1.75 & 76.41 & 2.26 & 0.24 \\
CelNFs-IL 25 ${ }^{\circ} \mathrm{C}$ & 0.056 & 1.08 & 43.75 & 2.47 & 0.28 \\
CelNFs-IL $35^{\circ} \mathrm{C}$ & 0.050 & 0.84 & 40.62 & 3.61 & 0.48 \\
\hline
\end{tabular}

$\mathrm{CrI}$ is the crystallinity index of the material (determined from the area ratio of the characteristic bands from the FTIR spectra, proportional to the content of cellulose I and cellulose II from the material).

LOI is the lateral order index of the material, proportional to the cellulose I content in the fibers (determined from FTIR spectroscopy).

$\mathrm{Cr}$ is the absolute crystallinity of the material, determined from the XRD diffractogram, as total contribution of the cellulose I and cellulose II anomer. $L$ represents the apparent cellulose crystallite dimensions, determined from the XRD diffractogram, relative to that of the defect-free $100 \%$ crystalline cellulose I anomer.

$X$ represents relative proportion of cellulose crystallite interior chains, related to more tight packing of the cellulose architecture. As structure modification and functionalization of cellulose occur, $X$ values also increase.

and the $1156 \mathrm{~cm}^{-1}$ bands (Table 1) [21]. The intensity of the $1156 \mathrm{~cm}^{-1}$ band has been found to remain constant under several different irradiation conditions so it has been used as reference in this study.

The lateral order index of cellulose decreases through IL treatment, suggesting a relative decrease with up to $45 \%$ of the cellulose I content in the fibers in favor of the dominating amorphous cellulose II anomer. This structural modification is confirmed also by the decrease in the crystallinity index of cellulose, as determined from both FTIR and XRD data. The formation of the dominatingly amorphous cellulose II anomer seems to favor the functionalization, due to the improved accessibility of the IL to the $-\mathrm{OH}$ groups of cellulose.

The FTIR spectra of IL-treated CelNF fibers (Figure 2(a)) reveal the increase in the relative intensity (reported to the band at $895 \mathrm{~cm}^{-1}$ ) of the alkyl stretching bands centered at $2859-2893 \mathrm{~cm}^{-1}$ domain with $50 \%$ (for $25^{\circ} \mathrm{C}$ ) and $97 \%$ (for $35^{\circ} \mathrm{C}$ ), the relative decrease in the intensity of the $\mathrm{OH}$ stretching bands at $3120-3350 \mathrm{~cm}^{-1}$ (with $36 \%$ and $44 \%$ for $25^{\circ} \mathrm{C}$ and $35^{\circ} \mathrm{C}$, resp.) reported to reference CelNF, and the appearance of a weak shoulder at 3122 and $3148 \mathrm{~cm}^{-1}$, respectively (ascribed to $\mathrm{H}-\mathrm{C}(4)$ and $\mathrm{H}-\mathrm{C}(5)$ vibration from the imidazolium ring). These modifications could be ascribed to the grafting of carbonyl groups bearing moieties and/or (poly)hydroxylated imidazolium moieties on the surface of the nanofibrillated cellulose material, possibly through hemi(acetal) or ether bonds, respectively. From these two possible linkage modes, acetalization is the most probable, because of the milder required reaction conditions. Possible new acetal/ether bonds appear also as weak shoulders centered at 1056 (for $25^{\circ} \mathrm{C}$ ) and $1060 \mathrm{~cm}^{-1}\left(35^{\circ} \mathrm{C}\right)$ and at $1516 \mathrm{~cm}^{-1}$ (at $35^{\circ} \mathrm{C}$ ) they could be formed [31] owing to the weakly acidic $\mathrm{pH}$ of the EB-irradiated IL $(\sim 5,8)$. Also, the presence of the bands from $1575 \mathrm{~cm}^{-1}\left(25^{\circ} \mathrm{C}\right)$ and at $1579 \mathrm{~cm}^{-1}$ (at $35^{\circ} \mathrm{C}$ ) attributed to plane $\mathrm{C}-\mathrm{C}$ and $\mathrm{C}-\mathrm{N}$ symmetric and asymmetric stretching of the imidazole ring from the IL [29] serves as possible supplementary indication of CelNFs functionalization. Also, from Figure 2(c), it could be seen that the nonirradiated IL treatment of the CelNFs at $35^{\circ} \mathrm{C}$ is responsible for a more pronounced decrease in the crystallinity index of cellulose, with $31 \%$ more than in the case of the irradiated IL treatment at the same temperature. This could be due to imidazolium cation structure alteration for the case of EB irradiating, which has a lower cellulose restructuration ability. Also, for neat IL treatment of CelNFs at $35^{\circ} \mathrm{C}$, no supplementary bands appear in the spectrum of cellulose nanofibers, in comparison with the initial (untreated) CelNFs, which sustain cellulose functionalization with the reactive byproduct(s) of electron-beam irradiation of $\mathrm{HMIMBF}_{4}$. Only a relative increase of the absorption at $1700-1750 \mathrm{~cm}^{-1}$ region could be registered, possibly due to more pronounced cellulose end-groups oxidation with atmospheric oxygen, in comparison with the irradiated ILtreated samples.

Also, determined from Figure 2(d), it can be seen that there are no significant changes between the FTIR spectra of neat IL-functionalized cellulose and the same fibers submitted to thermal treatment at $230^{\circ} \mathrm{C}$ and $1 \mathrm{~h}$. The only modifications that occur are related to a slight reduction in the overall intensities of the absorption bands. The relative intensity of the band associated with the carbonyl groups $\left(1765-1715 \mathrm{~cm}^{-1}\right)$ has only a $2.3 \%$ increase, by comparing to the initial functionalized cellulose nanofibers, which means that the IL-grafted cellulose does not degrade in a significant manner, while embedding in HDPE and thermoforming the composites.

As presented in Figure 3, the XRD pattern of the untreated CelNFs is consistent with that of cellulose I (the diffraction peaks at $15.36^{\circ}$ and $16.65^{\circ}$ ), especially the $\mathrm{I}_{\beta}$ form (the (1-10) plane at $\left.15.36^{\circ}\right)[21,32]$. After treatment with irradiated IL, cellulose I content from the fibers decreases, as determined from the relative crystallinity decrease of $38 \%$ (for $25^{\circ} \mathrm{C}$ treatment) and $41 \%$, respectively (for $35^{\circ} \mathrm{C}$ treatment), in comparison with the untreated fibers.

The decrease in crystallinity is probably due to the progressively increased swelling of cellulose in the CNFs samples by the IL. With increasing temperature, the fraction of cellulose swollen with IL increases, as well as the grafting of imidazolium moieties to cellulose, evidenced also by the increase in the apparent crystallite size of cellulose (Table 1). The swollen functionalized cellulose thus transforms into a dominatingly disordered structure upon displacement of IL with water, the bulky alkylimidazolium chains impeding its crystallization, evidenced by the decreasing of the relative proportion of cellulose crystallite interior chains $(X)$ with temperature (Table 1). An increased value of $X$ could represent a tighter packing of the cellulose macromolecules in the unit cell, as it is registered for the neat CNFs, while lower values could signify a looser packing of the macromolecules, determined by the imidazolium moieties.

The water vapor sorption of reference and grafted CelNFs as a function of relative humidity of the environment are presented in Figure 4. 


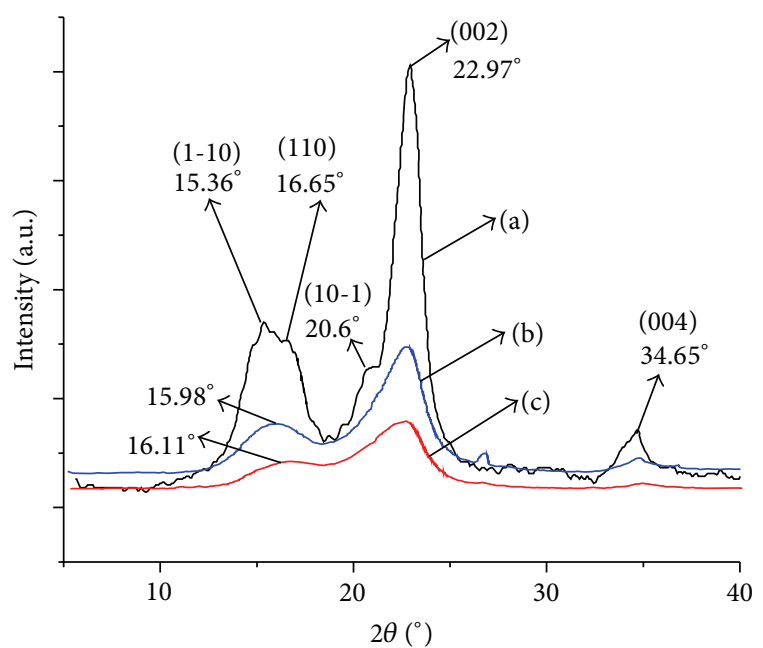

FIGURE 3: XRD diffractograms of reference and irradiated IL-treated CelNFs: (a) reference CelNFs; (b) IL-treated CelNFs $25^{\circ} \mathrm{C}$; (c) ILtreated CelNFs $35^{\circ} \mathrm{C}$.

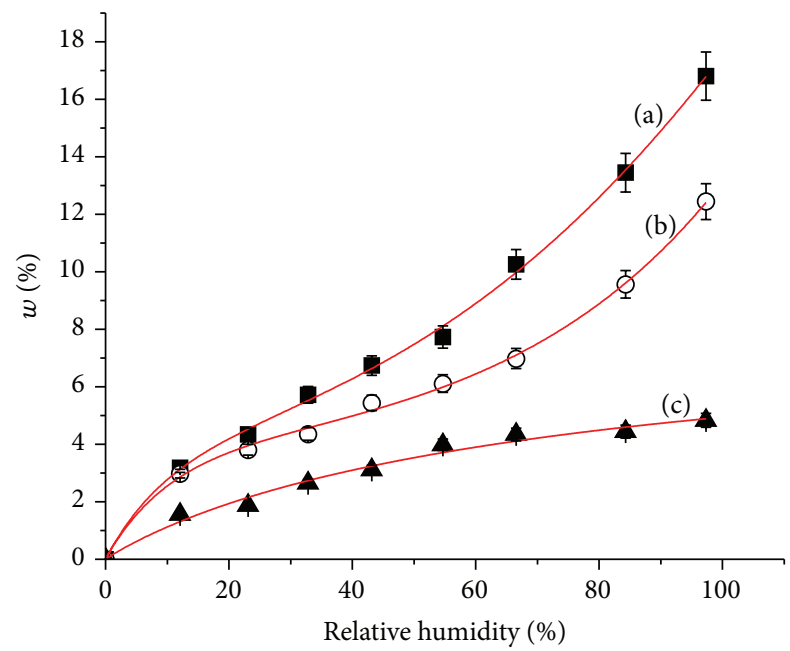

FIGURE 4: Water sorption isotherms of reference and IL-treated CelNFs: (a) reference CelNFs; (b) IL-treated CelNFs at $25^{\circ} \mathrm{C}$; (c) ILtreated CelNFs at $35^{\circ} \mathrm{C}$.

The functionalized CelNFs, possessing a dominatingly amorphous character, would be expected to present higher water vapors relative uptakes than the crystalline CelNF reference. The experimental data presented in Figure 4 suggest that the fibers functionalized at $35^{\circ} \mathrm{C}$ present water vapors uptake values with $50-70 \%$ lower and a water vapors uptake rate with 50\% lower than those of reference CelNFs sample submitted to the same experimental conditions, which could be explained by the hydrophobisation of cellulose through the dominatingly hydrophobic lateral alkyl chains of the imidazolium moieties.

The SEM micrographs from Figure 5 suggest an improved adherence of the cellulose nanofibers with the HDPE matrix. Even if cellulose nanofibril associations may occur, the analysis of the IL-treated CelNFs at $35^{\circ} \mathrm{C}$ composite does not evidence deboning or delamination, such as in the case of neat CelNFs-HDPE composite, where visible structural defects (voids, delamination) are present. Also, by determining the roughness of the composites surface using the image analysis technique [17], the nonirradiated CelNFHDPE composite presents an average roughness of 40 pixels, while the functionalized CelNF-HDPE composite has an average surface roughness of 10.87 pixels, further evidencing the CelNFs improved embedding in the polymer matrix. The improved compatibility of the CelNFs with the nonpolar HDPE matrix could be due to cellulose functionalization with irradiated $\mathrm{HMIMBF}_{4}$.

\section{Conclusions}

Cellulose nanofibers obtained by the traditional acid hydrolysis method have been obtained using cotton linters as source. The obtained cellulose nanofibers have been functionalized at $25^{\circ} \mathrm{C}$ and $35^{\circ} \mathrm{C}$, respectively, with hydroxylated imidazolium moieties generated through electron-beam irradiation of 1-hexyl-3-methylimidazolium tetrafluoroborate, as it has been demonstrated through the occurrence of a new band, centered at $\sim 3400 \mathrm{~cm}^{-1}$ in the FTIR spectrum of the electron-beam irradiated ionic liquid. The functionalization determines the hydrophobisation of cellulose, as resulting from the water vapors uptake values with $50-70 \%$ lower than those of reference CelNFs sample submitted to the same experimental conditions. The functionalization of the cellulose with the irradiated alkylimidazolium ionic liquid determines improved adhesion of the nanofibers with nonpolar matrices, such as high density polyethylene, as determined from more uniform covering of the fibers surface with the polyolefin matrix as determined from the scanning electron micrographs, thus constituting a possible alternative to other physical and chemical cellulose functionalization methods. The functionalized CelNFs, possessing a dominatingly amorphous character as determined from XRD diffractograms, would be expected to present higher water vapors relative uptakes than the crystalline CelNF reference.

Due to the low vapor pressure of ionic liquids, functionalization of cellulose with these compounds could be considered a mild (green) process, which could contribute to the developing of materials with improved properties and prolonged lifecycle. Further studies are still needed, in order to determine the stability of the functionalized material under various conditions, its possible antimicrobial character, and the influence of various electron-beam irradiation doses on the grafting ability to the cellulosic material.

\section{Competing Interests}

The authors declare that they have no competing interests.

\section{Acknowledgments}

This work was supported by a grant of the Romanian National Authority for Scientific Research and Innovation, CNCSUEFISCDI, Project no. PN-II-RU-TE-2014-4-0173. 


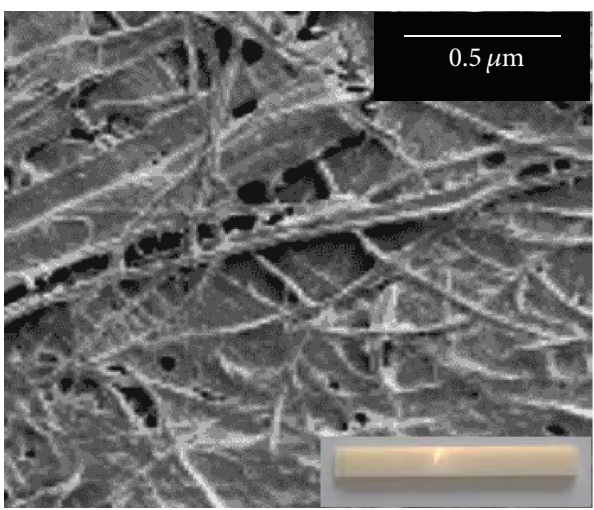

HDPE-reference CelNFs composite

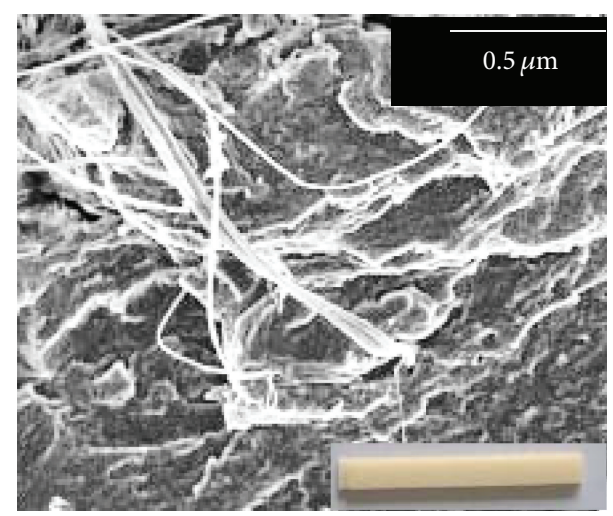

HDPE-HMIMBF 4 treated CelNFs composite

Figure 5: SEM micrographs of CelNFs-HDPE composites.

\section{References}

[1] K. Oksman, Y. Aitomäki, A. P. Mathew et al., "Review of the recent developments in cellulose nanocomposite processing," Composites Part A: Applied Science and Manufacturing, vol. 83, pp. 2-18, 2016.

[2] J. Zhao, J. Zhang, P. Hu et al., "A sustainable and rigid-flexible coupling cellulose-supported poly(propylene carbonate) polymer electrolyte towards $5 \mathrm{v}$ high voltage lithium batteries," Electrochimica Acta, vol. 188, pp. 23-30, 2016.

[3] L. Tang and C. Weder, "Cellulose whisker/epoxy resin nanocomposites," ACS Applied Materials and Interfaces, vol. 2, no. 4, pp. 1073-1080, 2010.

[4] M. Börjesson and G. Westman, "Crystalline nanocellulosepreparation, modification, and properties," in CelluloseFundamental Aspects and Current Trends, M. Poletto and H. L. Ornaghi, Eds., InTech Open, Rijeka, Croatia, 2015.

[5] S. Kamel, "Nanotechnology and its applications in lignocellulosic composites, a mini review," Express Polymer Letters, vol. 1, no. 9, pp. 546-575, 2007.

[6] R. J. Moon, A. Martini, J. Nairn, J. Simonsen, and J. Youngblood, "Cellulose nanomaterials review: structure, properties and nanocomposites," Chemical Society Reviews, vol. 40, no. 7, pp. 3941-3994, 2011.

[7] D. Klemm, D. Schumann, F. Kramer et al., "Nanocelluloses as innovative polymers in research and application," in Polysaccharides II, vol. 205 of Advances in Polymer Science, pp. 49-96, Springer, Berlin, Germany, 2006.

[8] K. Kolářová, V. Vosmanská, S. Rimpelová, and V. Švorčík, "Effect of plasma treatment on cellulose fiber," Cellulose, vol. 20, no. 2, pp. 953-961, 2013.

[9] V. K. Varshney and S. Naithani, "Chemical functionalization of cellulose derived from nonconventional sources," in Cellulose Fibers: Bio- and Nano-Polymer Composites, S. Kalia, B. S. Kaith, and I. Kaur, Eds., pp. 43-60, Springer, Berlin, Germany, 2011.

[10] E. Espino-Pérez, S. Domenek, N. Belgacem, C. Sillard, and J. Bras, "Green process for chemical functionalization of nanocellulose with carboxylic acids," Biomacromolecules, vol. 15, no. 12, pp. 4551-4560, 2014.

[11] A. Moldovan, S. Patachia, C. Vasile, R. Darie, E. Manaila, and M. Tierean, "Natural fibres/polyolefins composites (I) UV and electron beam irradiation," Journal of Biobased Materials and Bioenergy, vol. 7, no. 1, pp. 58-79, 2013.
[12] J. D. Holbrey and R. D. Rogers, "Green industrial applications of ionic liquids: technology review," in Ionic Liquids, vol. 818 of ACS Symposium Series, pp. 446-458, American Chemical Society, Washington, DC, USA, 2002.

[13] M. Liu, Z. Wang, J. Mei et al., "A facile functionalized routine for the synthesis of imidazolium-based anion-exchange membrane with excellent alkaline stability," Journal of Membrane Science, vol. 505, pp. 138-147, 2016.

[14] S. Barthel and T. Heinze, "Acylation and carbanilation of cellulose in ionic liquids," Green Chemistry, vol. 8, no. 3, pp. 301306, 2006.

[15] C. Croitoru, S. Patachia, A. Porzsolt, and C. Friedrich, "Effect of alkylimidazolium based ionic liquids on the structure of UVirradiated cellulose," Cellulose, vol. 18, no. 6, pp. 1469-1479, 2011.

[16] A. Cieniecka-Rosłonkiewicz, J. Pernak, J. Kubis-Feder, A. Ramani, A. J. Robertson, and K. R. Seddon, "Synthesis, anti-microbial activities and anti-electrostatic properties of phosphonium-based ionic liquids," Green Chemistry, vol. 7, no. 12, pp. 855-862, 2005.

[17] C. Croitoru, S. Patachia, N. Cretu, A. Boer, and C. Friedrich, "Influence of ionic liquids on the surface properties of poplar veneers," Applied Surface Science, vol. 257, no. 14, pp. 6220-6225, 2011.

[18] A. P. Abbott, T. J. Bell, S. Handa, and B. Stoddart, "O-Acetylation of cellulose and monosaccharides using a zinc based ionic liquid," Green Chemistry, vol. 7, no. 10, pp. 705-707, 2005.

[19] S. Patachia and C. Croitoru, "Potential applications of ionic liquids in ecologic wood processing," ProLigno, vol. 9, no. 4, pp. 211-216, 2013.

[20] M. Abu-Rous, E. Ingolic, and K. C. Schuster, "Visualization of the nano-structure of Tencel (Lyocell) and other cellulosics as an approach to explaining functional and wellness properties in textiles," Lenzinger Berichte, vol. 85, pp. 31-37, 2006.

[21] J. X. He, Y. Y. Tang, and S. Y. Wang, "Differences in morphological characteristics of bamboo fibres and other natural cellulose fibers: studies on X-ray diffraction, solid state C-13-CP/MAS NMR, and second derivative FTIR spectroscopy data," Iranian Polymer Journal, vol. 16, pp. 807-818, 2007.

[22] C. Croitoru and S. Patachia, "Biocomposites obtained from wood saw dust using ionic liquids," Acta Chemica Iasi, vol. 22, no. 2, pp. 113-134, 2014. 
[23] L. Greenspan, "Humidity fixed points of binary saturated aqueous solutions," Journal of Research of the National Bureau of Standards A, vol. 81, no. 1, pp. 90-96, 1977.

[24] B. Hinterstoisser and L. Salmén, "Application of dynamic 2D FTIR to cellulose," Vibrational Spectroscopy, vol. 22, no. 1-2, pp. 111-118, 2000.

[25] T. Kondo, "The assignment of IR absorption bands due to free hydroxyl groups in cellulose," Cellulose, vol. 4, no. 4, pp. 281292, 1997.

[26] A. C. O'Sullivan, "Cellulose: the structure slowly unravels," Cellulose, vol. 4, no. 3, pp. 173-207, 1997.

[27] V. Vosmanská, K. Kolářová, S. Rimpelová, and V. Švorčík, "Surface modification of oxidized cellulose haemostat by argon plasma treatment," Cellulose, vol. 21, no. 4, pp. 2445-2456, 2014.

[28] V. Vosmanská, R. A. Barb, K. Kolářová, S. Rimpelová, J. Heitz, and V. Švorčík, "Effect of VUV-excimer lamp treatment on cellulose fiber," International Journal of Polymer Analysis and Characterization, vol. 21, no. 4, pp. 337-347, 2016.

[29] A. Chowdhury and S. T. Thynell, "Confined rapid thermolysis/FTIR/ToF studies of methyl-amino-triazolium-based energetic ionic liquids," Thermochimica Acta, vol. 505, no. 1-2, pp. 33-40, 2010.

[30] P. A. Pieniazek and J. Stangret, "Hydration of tetraethylammonium tetrafluoroborate derived from FTIR spectroscopy," Vibrational Spectroscopy, vol. 39, no. 1, pp. 81-87, 2005.

[31] C. Croitoru, S. Patachia, F. Doroftei, E. Parparita, and C. Vasile, "Ionic liquids influence on the surface properties of electron beam irradiated wood," Applied Surface Science, vol. 314, pp. 956-966, 2014.

[32] T. Kondo, "Hydrogen bonds in regioselectively substituted cellulose derivatives," Journal of Polymer Science, Part B: Polymer Physics, vol. 32, no. 7, pp. 1229-1236, 1994. 

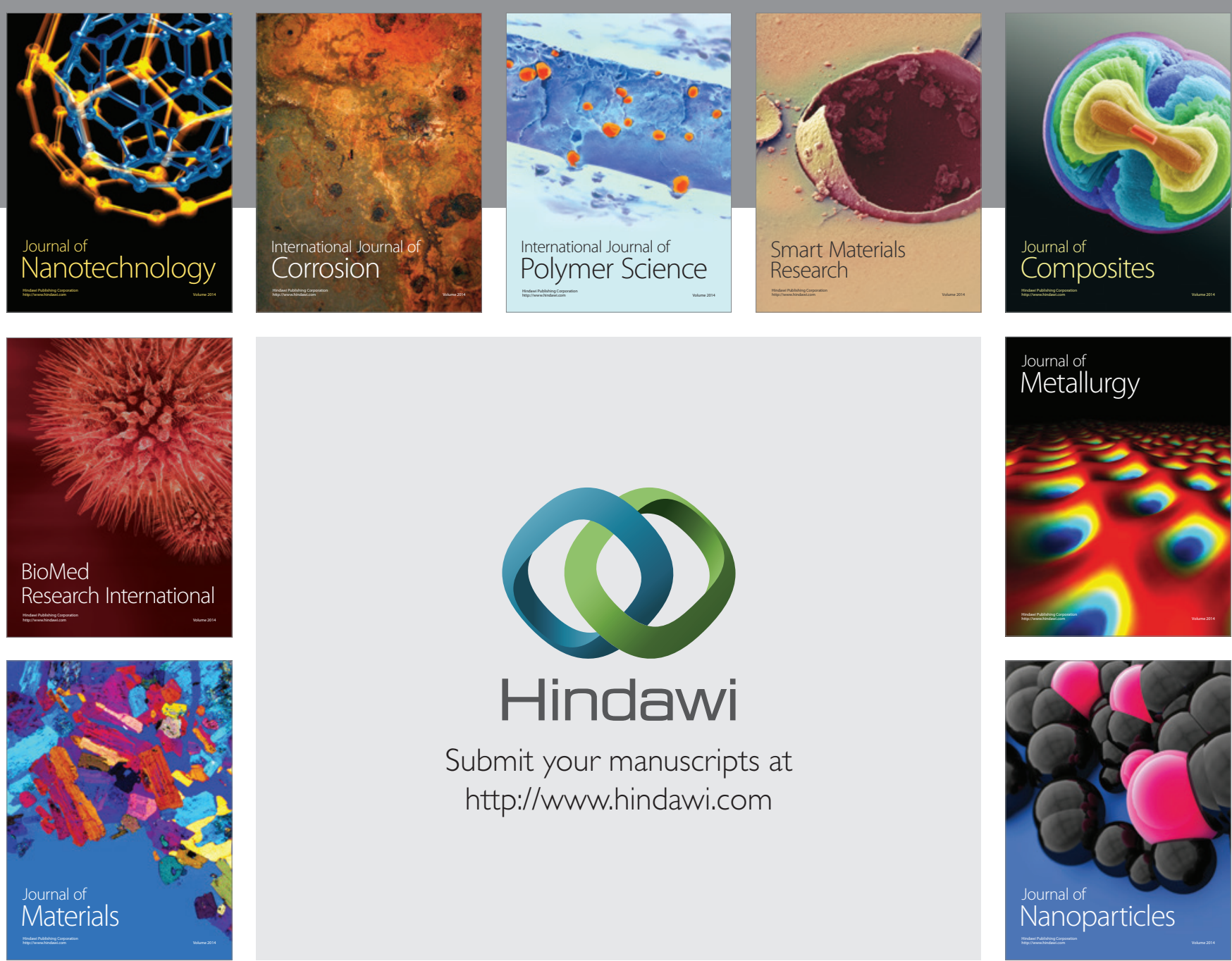

\section{Hindawi}

Submit your manuscripts at

http://www.hindawi.com

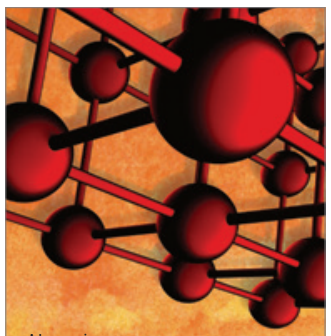

Materials Science and Engineering
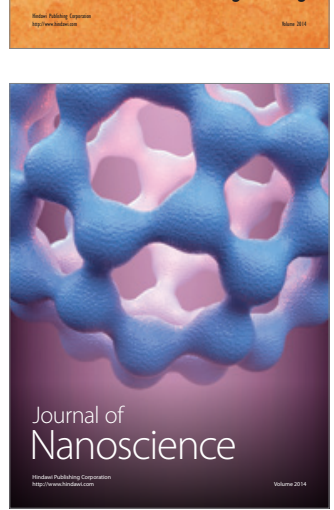
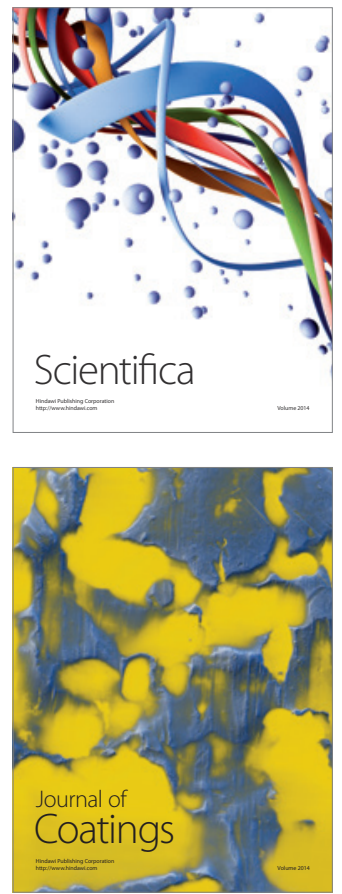
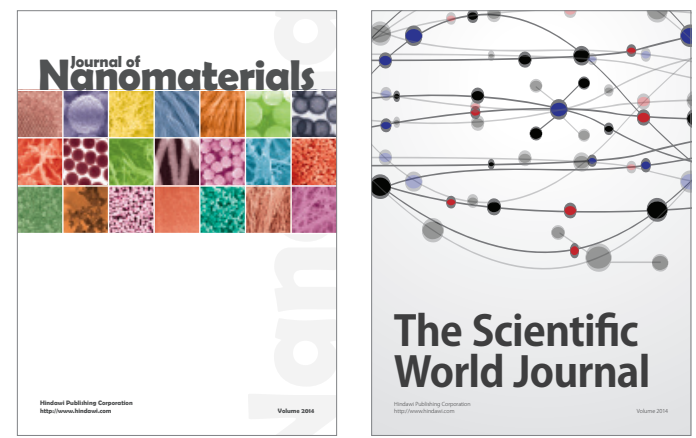

The Scientific World Journal
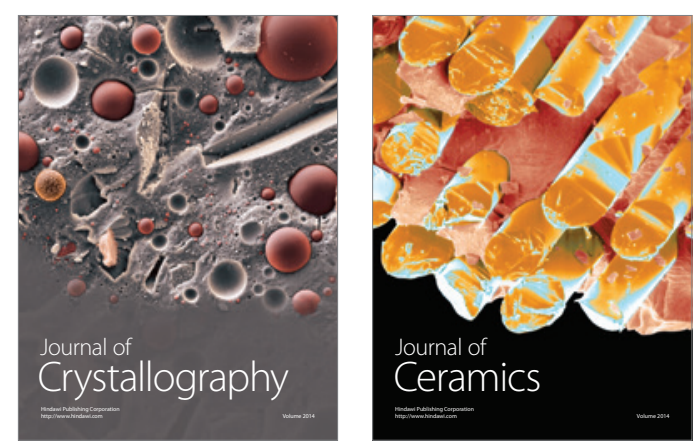
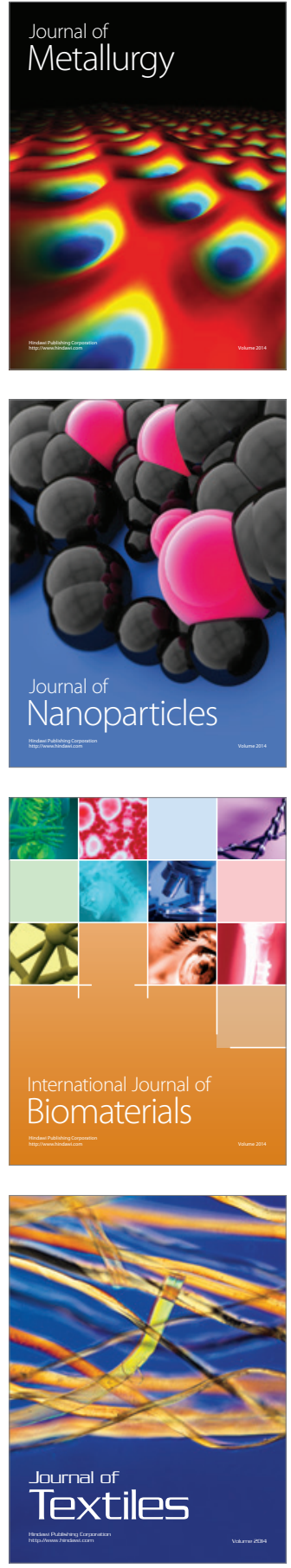